\title{
WORKING MEMORY AS A CONSTRUCT IN COGNITIVE SCIENCE: AN ILLUSTRIOUS PAST AND A HIGHLY PROMISING FUTURE
}

\author{
Satoru SAITO \\ Kyoto University, Japan \\ and \\ John N. TOWSE \\ Lancaster University, UK
}

\begin{abstract}
Working memory has been an important concept for psychological science for over 30 years, taking its modern form and inspiration from the work of Baddeley and Hitch (1974). Whilst our collective understanding of the term has evolved and diversified, we show that working memory still remains highly relevant to issues in cognition; contemporary research indicates how both theoretical models and the concept of working memory has much to offer the research discipline. We introduce five empirical studies for this special issue on working memory and show how each paper contributes to the broader understanding of cognition. More specifically these papers constrain ongoing debates about the domain-specific nature of short-term and working memory, the binding of different types of representations, the nature of executive control, and the role of working memory in action control. We attempt to place these four research themes under a larger research framework into which the five experimental articles are located.
\end{abstract}

Key words: memory, working memory, dual task methodology, working memory span

The concept of working memory, the system that supports the transient retention of stimuli and its transformation in the service of cognition, is now central to psychological science. So much so that one of the seminal articles that launched this notion in its historically modern form, the work of Baddeley and Hitch (1974), was identified in a survey of academics as being one of the 100 most influential papers in cognitive science in the last millennium (Millennium Project ${ }^{1}$ ). The scope of the concept has moved well beyond its initial purview as an account of dual task data in cognition.

The writing of this paper was supported by a Grant-in-Aid for Scientific Research (\# 19530655) to SS from the Ministry of Education, Culture, Sports, Science, and Technology in Japan, and the manuscript was prepared whilst JNT was a research visitor at the University of Colorado at Boulder. We thank Akira Miyake and Masanobu Takahashi for helpful comments on the earlier version of this paper.

Correspondence concerning this article should be addressed to Satoru Saito, Department of Cognitive Psychology in Education, Graduate School of Education, Kyoto University, Yoshida-Honmachi, Sakyo-ku, Kyoto, 606-8501, Japan. Electronic mail may be sent to S.Saito@mbox.kudpc.kyoto-u.ac.jp

${ }^{1}$ The Millennium Project conducted at the Center for Cognitive Sciences, the University of Minnesota has provided a list of the 100 most influential studies in cognitive science from the 20th century. See, the following webpage, http://www.cogsci.umn.edu/OLD/calendar/past_events/millennium/home.html 
Moreover, there can be little doubt that at the time of writing this editorial, Alan Baddeley, a key contributor to current theoretical and empirical work, is among the most widely known and respected British experimental psychologists throughout the discipline. Formal bibliometric measures of impact and status of articles and individuals are often crude and unsatisfying - yet they may also give a broad sense of accomplishment. That is, measures of citations counts can point to the reach of a piece of work insofar as it is difficult to see how an article could get a very high number of citations if it were useful only to a small circle of researchers. At the time of composing this introduction, Baddeley (1986) had over 4,000 citations ${ }^{2}$. We have tried to find other works in psychology (and not just cognitive psychology) with similar impact. In essence, although we have identified several papers with substantial citations counts, this work is basically unequalled. Regardless of whether all these citations accurately depict Baddeley's working memory model, this citation estimation offers a simple but dramatic demonstration of how the concept has captured something of fundamental relevance about cognition. An alternative bibliometric measure is the 'h-index' (Herfindahl index; Hirsh, 2005), which is designed to assess the distribution of citations for an individual across papers and gives an approximate measure of a scholar's impact. This too confirms that Alan Baddeley is a central contributor to psychological knowledge. Since working memory is much more than just the work of one individual, it becomes rapidly apparent that this concept is core to research in cognitive science.

Yet, why all this fuss? After all, models of immediate memory had been proposed beforehand, and alternative formulations have been considered in the past 30 years. So what is so special about working memory? We believe that there are many reasons for the sustained interest in this particular concept and we focus on two factors here. First, working memory can be treated as a general concept that promotes the consideration of immediate memory in the service of cognition - the notion of WMG, or Working Memory General (Baddeley, 1986). Second, working memory can be employed as a specific architectural account of how retention and modification might take place- the notion of WMS, the Specific model of Working Memory (for an elaborated discussion of this WMG/WMS distinction, see Towse, Hitch, \& Horton, in press. For other models of working memory, see for example Cowan, 2005; Miyake \& Shah, 1999). We are pleased to note that both these perspectives are represented in articles for the special issue, with an emphasis on WMS that draws upon Baddeley's model. Five experimental papers both tackle new issues with innovative designs, as well as revisit old questions through fresh eyes. In what follows, we attempt to position these five papers into a larger research framework.

The family of procedures known collectively as working memory span paradigms have been used from the outset to address issues of individual differences, as well as to help articulate theoretical accounts of 'complex cognition' (see Conway et al., 2005; Conway, Jarrold, Kane, Miyake \& Towse, 2007; Miyake 2001). The working memory

\footnotetext{
${ }^{2}$ We have used informal methods of reaching this figure such as calculations from Google scholar, as well as commercial databases, and reached the same conclusion.
} 
span paradigm is rich and subtle, supporting a wide variety of theoretical positions. They were designed to provide tests of the capacity to carry out "processing" and "storage" operations simultaneously (Daneman \& Carpenter, 1980). In this sense, working memory span tasks represent signatures of WMG. They have been widely deployed in the study of adults but they have also been relevant to many studies with children and across development, as well as among normal and abnormal groups.

Important to the tradition of WMS, the specific multi-component model of working memory, is a dual-task or interference paradigm (see Andrade, 2001). Whilst working memory span tasks are sometimes treated as dual task paradigms, we are referring in this context to common procedures such as articulatory suppression (the repeated vocalisation of a task -irrelevant word or phrase), finger or foot tapping (either repetition of the same motoric action or a simple sequence), and attention to visual stimuli (whether irrelevant pictures or visual noise). The cumulative impact from many working memory studies with these and other interference tasks is that there is a substantial repository of knowledge about their function, which means that they can be productively applied to new tasks.

These two approaches, working memory span and concurrent task requirements may seem quite distinct, but we regard them as complementary and important adjuncts to each other. Indeed, we argue that the contents of the special issue show how each can help to understand better issues in cognitive psychology. In particular, this special issue contributes to the ongoing debates about the domain specific nature of STM and WM, binding of different types of representations, executive control, and the role of WM in action control.

\section{Domain specific buffers in WM}

Interference tasks support the notion of domain-specific buffers or stores in working memory. Double dissociations in the pattern of performance changes are especially informative and Andrade and Donaldson (2007) provide a good example of this approach in this special issue. They showed that olfactory representations are dissociable from verbal or visuo-spatial memories through two experiments in which participants performed two memory tasks from the same or different domains. Working within more established notions of the domain-specific buffer known as the visuo-spatial sketch pad, Burin, Irrazabal, and Quinn (2007) investigate the critical features of dynamic visual noise that contribute to its experimental profile. Their work helps to constrain theories of the locus of interference and thus the mechanisms of this system within working memory, which in turn allow a better appreciation of the similarities and differences between verbal and visuospatial memory. Paradoxically perhaps, the results from Burin et al (2007) on the one hand, and Cattaneo, Postma \& Vecchi (2007) on the other, both point to commonalities with verbal memory whilst at the same time showing that visuo-spatial memory is not isomorphic with verbal memory. The extent of the correspondences across modalities pose a challenge to research, but it is important to keep in mind a broad swathe of work in order to appreciate how this will be eventually resolved.

The research literature does not exhibit complete consensus over the question of 
whether we need to postulate separate memory (sub)systems based on a double dissociation. The apparent domain-specificity could be explained by similarity between two types of materials or representations (e.g., Cowan, 1999). Nonetheless it is certainly also consistent with the conclusion that there are different types of representations that include different features. This provides a bridge to another issue emerging from the special issue; the binding of different types of representations.

\section{Binding of representations in WM}

As mentioned above, dual-task studies support the notion of separate memory representations. Yet this generates a further topic that needs addressing; how these different types of representations can be bound or integrated into single tractable and coherent representations in terms of perceptual experience of current or remembered events. One recent mechanistic proposal that may contribute to an explanatory framework is that of the episodic buffer (Baddeley, 2000; Baddeley \& Hitch, 2000) a multi-modal store that is designed to handle representations from a variety of sources not only from immediate past and WM (e.g., Allen, Baddeley, \& Hitch, 2006) but also from long-term memory or LTM (Jefferies, Lambon Ralph, \& Baddeley, 2004). Other contributions to the explanation of binding issues have emerged from other researchers (e.g., Oberauer, 2006; Wheeler \& Treisman, 2002) who start at least from rather different perspectives. In this special issue, Cattaneo et al. (2007) examine the nature of representations for retention over the short-term through the picture superiority effect in an immediate serial reconstruction task and the binding of spatial and temporal information is one of the important issues in their work.

\section{Executive control and WM}

The initial deployment of working memory span tasks came from work among adults (e.g., Daneman \& Carpenter, 1980) and children (Case, Kurland \& Goldberg, 1982). The paradigm was initially thought to capture the functioning of the central executive system in working memory, trading resources between memory and processing operations (though whether the central executive does have a memory function has been called into doubt; Baddeley \& Logie, 1999). Since the central executive has also been argued to have a control function too (but see Towse \& Houston-Price, 2001), it is not surprising that adult and developmental researchers have explored the possible connections between working memory span performance and executive processes, including inhibition, in human cognition and action (e.g. Jarrold \& Bayliss, 2007; Kane \& Engle, 2003; Kane, Poole, Tuholski, \& Engle, 2006). In the current issue, Marton, Kelmenson, and Pinkhasova (2007) follow this research direction, examining the listening span (one of the family of working memory span tasks) and inhibitory control abilities in children with specific language impairment. Thus their work illustrates the relevant of complex span at the same time as it demonstrates how working memory has been applied to an understanding of developmental issues, including the trajectories in atypical development (see Jarrold, 2001). This is especially welcome because for some time working memory has been applied to issues of children's cognition (e.g. Halliday \& Hitch, 1988; Nicolson, 
1981) and Marton et al. (2007) show that this continues to be a fruitful line of enquiry to pursue.

\section{The role of WM in action control}

One topic that is more directly linked to executive functioning is action control, whereby processing is directed towards the current task goal and steered away from any prepotent but inappropriate responses (Kane \& Engle, 2003). Within the domain of executive functions, control has been thought of very much as a higher-level process, one that operates upon slave systems and related, subordinate operations. However, it is now becoming apparent that this distinction may be an oversimplification in some important respects. In particular, inner speech — often thought of as a prototypical phonological loop function-may help to control and guide performance (e.g., Baddeley, Chincotta, \& Adlam, 2001; Emerson \& Miyake, 2003; Saeki \& Saito, 2004). Saeki (2007) pursues this theme in the special issue by investigating how articulatory suppression can modulate longer-term influences of prepotent interference.

\section{Summary and supplements}

We doubt that many people at the time could have successfully predicted just how durable and far-reaching the article by Baddeley and Hitch (1974) would be, nor how interest would persist in working memory span tests as a measure of complex cognition (Daneman \& Carpenter, 1980). Yet the ideas have gone from strength to strength, and both the initial interest in the special issue and the papers that have been selected show that the topic of working memory still offers a productive and fertile environment in which psychological issues can be investigated.

Along with access to publication research funds, an anonymous personal donation allowed for this issue to be published whilst waiving the usual Journal printing fees that is necessarily levied on authors to cover conventional publication costs. The donation was in memory of an individual whose steadfast belief first in the inherent value of communication across cultures and languages, and secondly in the importance of remaining positive so as to overcome the inevitable hurdles in the way of such discussion, is rewarded by the contents of this issue, which to us wonderfully express these ideals.

\section{REFERENCES}

Allen, R. N., Baddeley, A. D., \& Hitch, G. J. 2006. Is the binding of visual features in working memory resource-demanding? Journal of Experimental Psychology: General, 135, 298-313.

Andrade, J. (Ed.). 2001. Working memory in perspective. Hove, UK: Psychology Press.

Andrade, J., \& Donaldson, L. 2007. Evidence for an olfactory store in working memory? Psychologia, 50, 76-89.

Baddeley, A. D. 1986. Working Memory. Oxford: Clarendon Press.

Baddeley, A. D. 2000. The episodic buffer: A new component of working memory? Trends in Cognitive Sciences, 4, 417-423.

Baddeley, A. D., Chincotta, D., \& Adlam, A. 2001. Working memory and the control of action: Evidence from task switching. Journal of Experimental Psychology: General, 130, 41-657. 
Baddeley, A. D., \& Hitch, G. J. 1974. Working memory. In G. Bower (Ed.), Psychology of learning and motivation VIII (pp. 47-90). New York: Academic Press.

Baddeley, A. D., \& Hitch, G. J. 2000. Development of working memory: Should the Pascual-Leone and the Baddeley and Hitch models be merged? Journal of Experimental Child Psychology, 77, 128-137.

Baddeley, A. D., \& Logie, R. H. 1999. Working memory: The multiple-component model. In A. Miyake \& P. Shah (Eds.), Models of working memory: Mechanisms of active maintenance and executive control (pp. 28-61). Cambridge, England: Cambridge University Press.

Burin D. I., Irrazabal, N., \& Quinn, J. G. 2007. Maintenance in visuo-spatial working memory. Psychologia, 50, 90-101.

Case, R., Kurland, M. D., \& Goldberg, J. 1982. Operational efficiency and the growth of short-term memory span. Journal of Experimental Child Psychology, 33, 386-404.

Cattaneo, Z., Postma, A., \& Vecchi, T. 2007. The picture superiority effect in working memory for spatial and temporal order. Psychologia, 50, 102-109.

Conway, A. R. A., Kane, M. J., Bunting, M. F., Hambrick, D. Z., Wilhelm, O., \& Engle, R. W. 2005. Working memory span tasks: A methodological review and user's guide. Psychonomic Bulletin \& Review, 12, 769-786.

Conway, A. R. A., Jarrold, C., Kane, M., Miyake, A., \& Towse, J. N. (Eds.). 2007. Variation in Working Memory. New York: Oxford University Press.

Cowan, N. 1999. An embedded-processes model of working memory. In A. Miyake \& P. Shah (Eds.), Models of working memory: mechanisms of active maintenance and executive control (pp. 62-101). New York: Cambridge University Press.

Cowan, N. 2005. Working memory capacity. Hove: Psychology Press.

Daneman, M., \& Carpenter, P. A. 1980. Individual differences in working memory and reading. Journal of Verbal Learning and Verbal Behavior, 19, 450-466.

Emerson, M. J., \& Miyake, A. 2003. The role of inner speech in task switching: A dual-task investigation. Journal of Memory and Language, 48, 148-146.

Halliday, M. S., \& Hitch, G. J. 1988. Developmental applications of working memory. In G. Claxton (Ed.), Growth points in cognition. New York: Routledge, Chapman \& Hall, Inc.

Hirsch, J. E. 2005. An index to quantify an individual's scientific research output. Proceedings of the National Academy of Sciences, 102, 16569-16572.

Jarrold, C. 2001. Applying the working memory model to the study of atypical development. In J. Andrade (Ed.), Working memory in perspective (pp. 126-150). Hove: Psychology Press.

Jarrold, C., \& Bayliss, D. M. 2007. Variation in working memory due to typical and atypical development. In A. R. A. Conway, C. Jarrold, M. J. Kane, A. Miyake, \& J. N. Towse (Eds.), Variation in Working Memory (pp. 134-161). New York: Oxford University Press.

Jefferies, E., Lambon Ralph, M. A., \& Baddeley, A. D. 2004. Automatic and controlled processing in sentence recall: The role of long-term and working memory. Journal of Memory and Language, 51, 623-643.

Kane, M. J., \& Engle, R. W. 2003. Working-memory capacity and the control of attention: The contributions of goal maintenance, response competition, and task set to Stroop interference. Journal of Experimental Psychology: General, 132, 47-70.

Kane, M. J., Poole, B. J., Tuholski, S. W., \& Engle, R. W. 2006. Working memory capacity and the top-down control of visual search: Exploring the boundaries of "executive attention". Journal of Experimental Psychology: Learning, Memory, and Cognition, 32, 749-777.

Marton, K., Kelmenson, L., \& Pinkhasova, M. 2007. Inhibition control and working memory capacity in children with SLI. Psychologia, 50, 110-121.

Miyake, A. 2001. Individual differences in working memory: Introduction to the special section. Journal of Experimental Psychology: General, 130, 163-168.

Miyake, A., Friedman, N. P., Emerson, M. J., Witzki, A. H., Howerter, A., \& Wager, T. 2000. The unity and diversity of executive functions and their contributions to complex "frontal lobe" tasks: A latent variable analysis. Cognitive Psychology, 41, 49-100.

Miyake, A., \& Shah, P. 1999. Models of working memory: mechanisms of active maintenance and executive control. New York: Cambridge University Press.

Nicolson, R. 1981. The relationship between memory span and processing speed. In M. P. Frieman, J. P. 
Das, \& N. O’Connor (Eds.), Intelligence and learning. New York: Plenum.

Oberauer, K. 2006. Binding and inhibition in working memory: Individual and age differences in short-term recognition. Journal of Experimental Psychology: General, 134, 368-387.

Saeki, E. 2007. Phonological loop and goal maintenance: Effect of articulatory suppression in number-size consistency task. Psychologia, 50, 122-131.

Saeki, E., \& Saito, S. 2004. Effect of articulatory suppression on task switching performance: Implications for models of working memory. Memory, 12, 257-271.

Towse, J. N., Hitch, G. J., \& Horton, N. (in press). Working memory as the interface between processing and retention: A developmental perspective. Advances in Child Development and Behavior.

Towse, J. N., \& Houston-Price, C. M. T. 2001. Reflections on the concept of the central executive. In J. Andrade (Ed.), Working memory in perspective (pp. 240-260). Hove: Psychology Press.

Wheeler, M. E., \& Treisman, A. M. 2002. Binding in short-term visual memory. Journal of Experimental Psychology: General, 131, 48-64.

(Manuscript received May 8, 2007; Revision accepted May 30, 2007) 